\title{
A review of materials currently used in orbital floor reconstruction
}

\author{
David Mok BSc ${ }^{1}$, Lucie Lessard MD², Carlos Cordoba MD ${ }^{1}$, Patrick G Harris MD ${ }^{1}$, Andreas Nikolis $\mathrm{MD}^{1}$
}

D Mok, L Lessard, C Cordoba, PG Harris, A Nikolis. A review of materials currently used in orbital floor reconstruction. Can J Plast Surg 2004;12(3):134-140.

\begin{abstract}
Orbital fractures are common fractures of the midface. As such, numerous techniques and materials exist for the repair of this region, each with inherent advantages and disadvantages. But does the ideal implant material exist? Should we stop and simply use readily available materials, or should the cycle of need and discovery continue? A comprehensive review of materials used in orbital reconstruction and possible new directions in orbital floor reconstruction are presented.
\end{abstract}

Key Words: Alloplasts; Autologous materials; Biomaterials; Orbital fracture

\section{Matériel actuellement utilisé pour la recons- truction du plancher orbital}

\begin{abstract}
Les fractures orbitales sont des fractures courantes qui peuvent souvent affecter le milieu du visage. C'est pourquoi il existe autant de techniques et de types de matériel pour en effectuer la réparation, chacun comportant ses inconvénients et ses avantages. Mais, disposons-nous de l'implant idéal? Devons-nous simplement nous contenter du matériel existant ou vaudrait-il mieux poursuivre sur la voie de la recherche et du développement? Le présent article fait une revue exhaustive du matériel actuellement offert pour la reconstruction orbitale et des nouvelles orientations possibles pour ce type d'intervention.
\end{abstract}

$\mathrm{F}$ ractures of the orbit are among the more common fractures - of the midface. As such, there exists a great deal of literature evaluating reconstruction of this region. There is still much debate about many aspects of the treatment of these injuries given the multitude of available materials and techniques for reconstruction.

Orbital fractures are the result of energy transmitted in the form of pressure or through direct mechanical stress to the orbital walls. As in most systems, it is the weakest area that will give in to such a load. This most commonly involves the medial wall and/or the orbital floor. A defect in these walls creates an opening into the ethmoid and/or maxillary sinuses through which orbital fat and other orbital contents can herniate, thereby increasing the orbital volume. This increase in volume has been shown to correlate linearly with the degree of enophthalmos that results from the injury. If orbital contents are pushed inferiorly, the globe should follow and result in hypoglobus. As well, extraocular muscle entrapment can occur, resulting in motility disturbances and diplopia. Other complications include nerve and vessel injury, and injury to the lacrimal system.

As with any soft tissue trauma, inflammation and edema are expected sequelae. Soft tissue swelling creates a dilemma for the treating clinician because it may compensate and mask the increase in orbital volume. As the swelling subsides, the degree of globe displacement becomes more apparent. Therefore, the decision to operate and the timing for surgery rely on clinical and radiographical evidence in the management of orbital fractures $(1,2)$. Numerous studies in the literature have evaluated the timing and method of repair.
Approaches to the repair of orbital floor fractures include transconjunctival, subciliary, mid-lower eyelid, infraorbital and, more recently, endoscopic transantral approaches $(3,4)$. Good exposure and adequate repair of the orbital wall defect have been proven possible in all of the above. However, there continues to be extensive discussion as to which approach has the best outcomes when complication rates, such as ectropion and scleral show, are evaluated.

Aside from surgical timing and the approach used, a third, equally important, factor in the management of orbital fractures remains the choice of the material used in the reconstruction. There exists an impressive number of publications describing orbital fracture repair with a considerable variety of materials that are autogenic, allogenic or alloplastic in nature. Because direct comparisons of the materials used are rare, it would be difficult to draw formal conclusions as to which material is best suited to repair these injuries. Surgeons choose materials they believe will give the best results with the lowest complication rates. The statements made in each publication are usually supported by the data presented to variable degrees, but each surgeon or group of surgeons has likely developed an expertise using a given material.

Regardless of the choice of material used in the repair, objective advantages and disadvantages must be weighed when one material is chosen over another. The present review will address these issues in a comprehensive and objective manner. The objective was to review the literature and discuss the various materials used in orbital floor repair, with emphasis on the advantages, disadvantages and possible new directions for biomaterial evaluation.

${ }^{1}$ Division of Plastic and Reconstructive Surgery, Centre Hospitalier de l'Université de Montreal; '2Division of Plastic and Reconstructive Surgery, McGill University Health Centre, McGill University, Montreal, Quebec

Correspondence: Dr Andreas Nikolis, Centre Hospitalier de l'Université de Montréal, Hôpital Notre Dame, Pavillon Deschamps, 5th étage, Porte F-5149, 1560 Sherbrooke East, Montreal, Quebec H2L 4M1. Telephone 514-890-8000 ext 23757, fax 514-738-1482,

e-mail an@DMResearch.com 
TABLE 1

Graft materials available for orbital fracture repair

\begin{tabular}{llc}
\hline Autologous materials & Allogenic materials & Alloplastic materials \\
\hline Bone & Irradiated bone & Nonmetallic, permanent \\
Cartilage & Lyophilized dura & Silastic sheets \\
Fascia lata & Lyophilized cartilage & Bioactive glass \\
Periosteal & Fascia lata & Marlex mesh \\
& Bovine bone & Porous polyethylene \\
& Teflon \\
& & Metallic, permanent \\
& Titanium \\
& Vitallium \\
& Resorbable materials \\
& Polylactic/polyglycolic \\
& acid copolymer \\
& Polydioxanone \\
& Polyglactin 910 \\
& polydioxanone
\end{tabular}

\section{MATERIALS AND METHODS}

A MEDLINE search was undertaken with key words including orbital blowout/floor fractures, complications and the various implant materials used in the repairs. The search was narrowed by searching for articles specifically investigating graft materials with outcome evaluations following clinical use.

\section{RESULTS AND DISCUSSION}

The general goal for orbital wall reconstruction is to restore the normal anatomical relations of the internal orbit while avoiding complications of the procedure and implant. Given the large number of graft materials available for orbital fracture repair, it is therefore important to analyze these materials within their respective categories. Grossly, graft material can be divided into autologous grafts, allogenic materials and alloplastic materials. Autologous grafts include bone and cartilage of varying origin. Allogenic materials include irradiated bone, lyophilized cartilage and lyophilized dura. The list of alloplastic materials is long and requires further subdivision into porous (nonmetallic), nonporous (metallic) and resorbable materials (Table 1).

\section{Autologous materials}

Bone grafts for the orbital floor have long been considered the standard treatment for orbital fracture repair. The principle of this approach requires an appropriate amount of autologous bone harvested from a donor site, which is shaped and inset to provide a rigid structural support in reconstructing the defect. Bone grafts have regained the favour of many craniofacial surgeons due, in part, to their biocompatibility. Donor sites include the split calvarial bone graft, rib, maxillary wall, mandibular symphysis, iliac crest, antral bone and coronoid process (1,5-11). The grafts can be placed as onlay grafts (12), fixated with a plate and screw (13), fixated with a lag screw or fixated in conjunction with an alloplastic material, such as titanium mesh or porous polyethylene sheets $(14,15)$ (Figures 1-5)

The advantages of autologous bone are its inherent strength and rigidity, and its vascularization potential (5). Because autologous bone grafts are incorporated as living tissue and do not elicit an immune reaction to self-antigens, foreign body

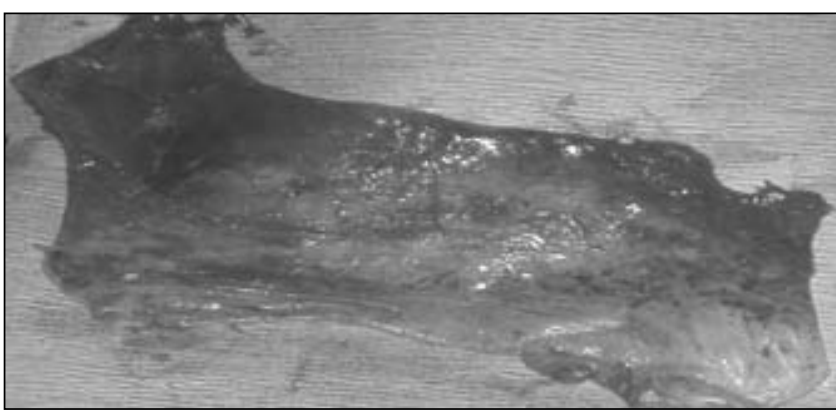

Figure 1) Tensor fascia lata graft

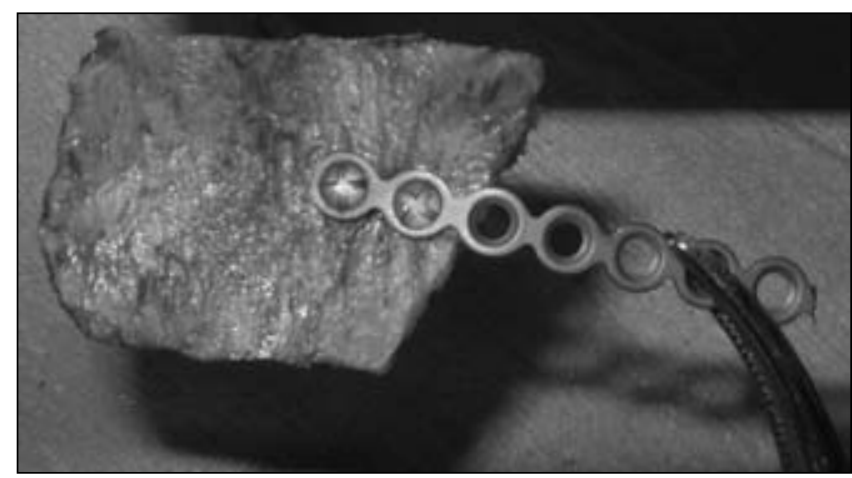

Figure 2) Split thickness cranial bone graft

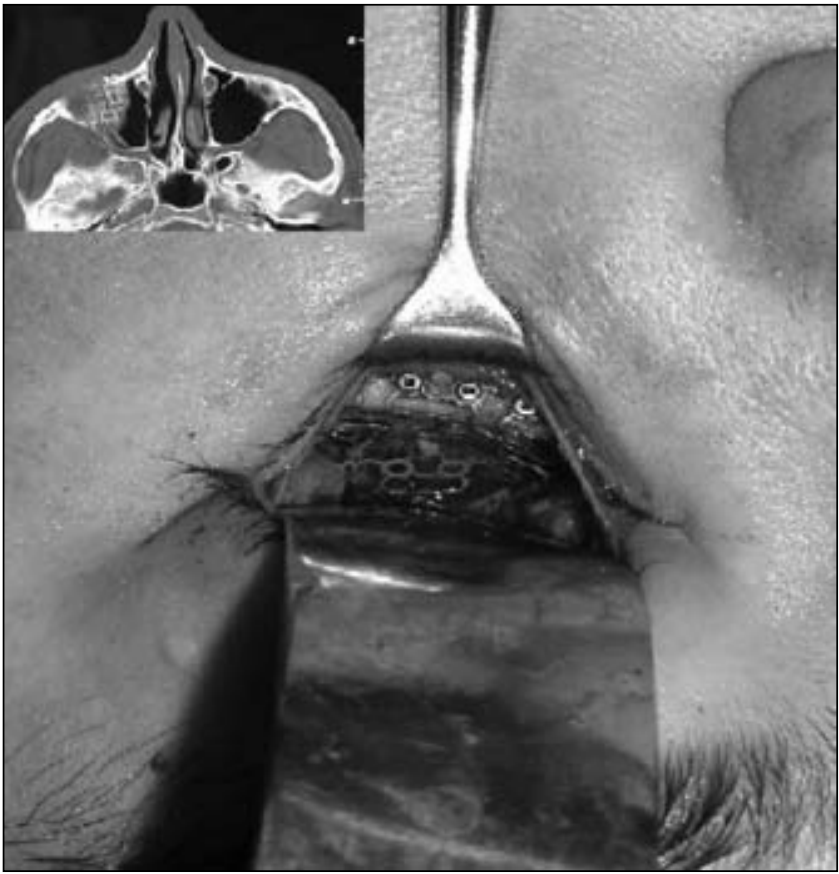

Figure 3) Composite photograph of titanium implant with postoperative computed tomography scan

reactions such as infection, extrusion, capsule formation and ocular tethering are minimized (5).

However, the use of autologous bone is associated with several less favourable aspects. First, bone is not always easy to form into the desired shape and can break if it is bent beyond its capacity. In 2003, Ellis and Tan (16) demonstrated better 


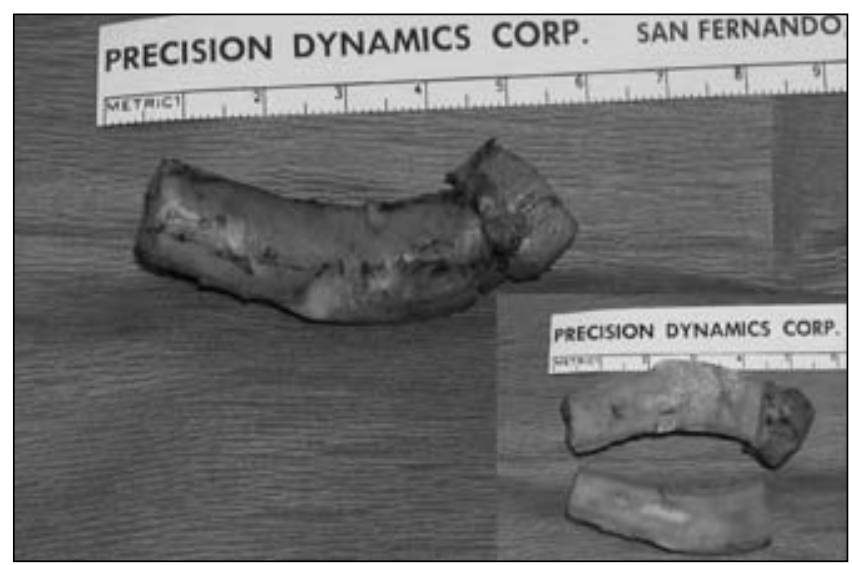

Figure 4) Rib cartilage graft

accuracy of reconstruction using titanium mesh than with cranial bone grafts. For large defects with fractures of multiple walls and disruption of bony buttresses, it is not always possible to use autologous bone as the sole material.

One of the major concerns of bone grafts is unpredictable graft resorption $(13,17-19)$. Bone grafts will resorb to a certain degree over time; however, the degree of resorption can be quite variable and, at times, unpredictable. The literature supports various methods for reducing bone resorption. Bone of membranous embryological origin is less prone to resorption than is bone of endochondral origin $(18,19)$. As well, cortical bone is many-fold more resistant to resorption than is cancellous bone (12). Another method to decrease graft resorption is via rigid fixation of the graft $(13,17,18)$, which likely facilitates ingrowth of the surrounding tissue and accelerates vascularization. The question of whether the use of a titanium mesh plate with a bone graft would increase graft resorption was answered with a histometric study (15) that showed no difference in the resorption of grafts with or without titanium mesh.

Further issues with autologous bone graft use relate to the harvesting of the graft from a remote donor site, including an increase in operating time and time under general anesthesia. As well, donor site morbidity is a concern. For the most part, the donor graft is harvested with few complications (5). General risks for the harvesting of a donor site include infection, hematoma, seroma, neurovascular injury, use of drains, increased time of recovery, increased postoperative pain, a bony defect at the donor site and an additional surface scar.

Certain donor sites are associated with site-specific complications. Rib grafts have been associated with pneumothorax and split calvarial bone grafts have been associated with dural tears, subarachnoid hemorrhages and intracerebral hematomas. In addition, there has been a case report of hemiparesis following an intracranial bleed $(6,7)$.

Another frequently used source of donor tissue for orbital floor reconstruction is cartilage. The more commonly used autologous cartilage grafts include nasal septum, rib cartilage and ear cartilage $(5,20,21)$. As with autologous bone, infection, extrusion, capsule formation and chronic inflammatory reactions are less prevalent than with alloplastic materials. Advocates of this material report that, in addition to the above benefits, cartilage is simple to harvest and shape, and provides adequate strength to support local tissues. In addition, this support is long-lasting, without evidence of resorption even after follow-up of 3.5 years (21).

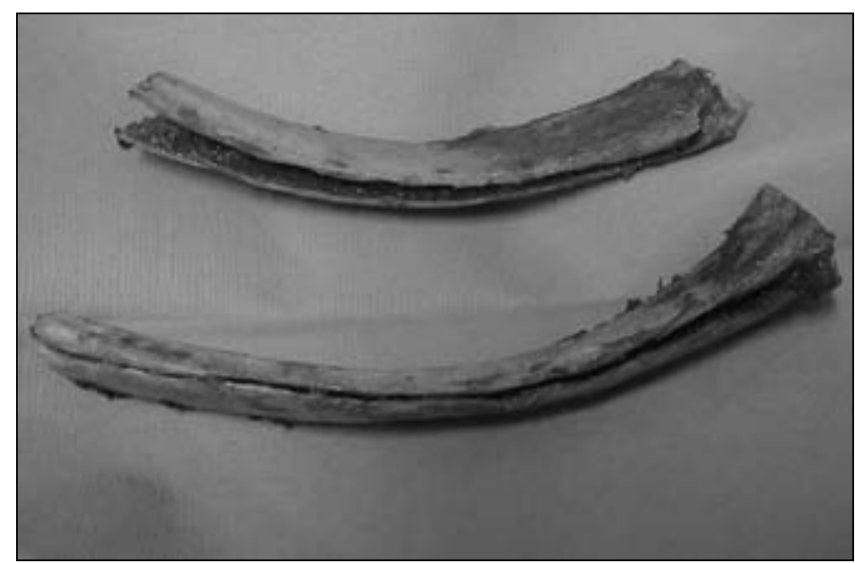

Figure 5) Split rib grafts

The use of septal cartilage grafts was presented in a case series (20) of 20 orbital floor reconstructions with reported uncomplicated harvesting, minimal donor site morbidity and a complication rate of $10 \%$, where the complications were not graft related (5\% enophthalmos and 5\% lower lid edema). As well, the graft has been shown to resist warping with time and provides excellent support. Conchal cartilage can be used to fill defects smaller than $2 \mathrm{~cm} \times 2 \mathrm{~cm}$, and has the advantage of the natural curvature of the concha fitting nicely with the orbital floor (21).

Although autologous cartilage offers some unique benefits as a graft material, its main limiting factor is donor tissue availability and, thus, its use should be limited for smaller orbital floor defects.

Other autologous materials that have been employed in orbital fracture repair include tensor fascia lata grafts and periosteal grafts (22). Although the number of cases in the literature is small (23), these grafts exhibit good results for small- to medium-sized defects (up to $2 \mathrm{~cm}^{2}$ ) and complication rates comparable with the other more commonly used materials.

\section{Allogenic materials}

Though less common in North America, some European centres have a preference for these materials (1). The advantages over autologous grafts include the lack of donor site morbidity, decreased operating room time, opportunity to prefabricate the implant and availability of tissue.

The allogenic materials that have been used are human dura matter, lyophilized cartilage, banked bone, fascia lata and heterogenic bovine bone graft (23-29).

A study (25) of orbital reconstruction with lyophilized dura on 55 patients demonstrated a one-year enophthalmos rate of $5.4 \%$ with no infections or extrusions. A review (26) of 77 isolated orbital floor fractures repaired with the same material reported a $20 \%$ enophthalmos rate without evidence of infection or extrusion.

Demineralized bone implants induce osteoconduction, resembling autologous bone grafts. They induce chemotaxis and differentiation of mesenchymal cells into chondroblasts. The bone scaffold and cartilage then ossify. Neigel and Ruzicka (24) reconstructed 31 traumatized orbits with demineralized bone and reported no graft-related complications.

A series of 20 patients received bovine heterologous bone grafts for repair of their orbital fractures (29). In vitro and 
in vivo biocompatibility studies demonstrated a good safety profile and, for the 20 patients in this study, there was no evidence of incompatibility, inflammation or infection.

While allogenic materials offer several attractive features, there exist specific disadvantages to their use. The resorption rate has been shown to be statistically higher than observed with autologous implants (5). There is a more worrisome potential complication with implants taken from a human donor - the possibility of disease transmission, such as HIV and the hepatitis $C$ virus $(30,31)$. In addition, the transmission of Creutzfekdt-Jakob disease has been reported in cadaveric dura transplantation $(32,33)$. Taguchi et al (34) proposed a procedure for the inactivation of this transmissible protein agent; however, as the mean incubation time for the disease is estimated to be 89 months and potentially longer, it would be difficult to prove its efficacy. The use of donor animals could overcome this potentially lethal problem.

\section{Permanent alloplastic materials}

Subsequent to the development of a direct approach to the orbital floor, a diverse group of alloplastic materials have been used for reconstruction of the fractured orbit. Generally, alloplastic materials eliminate donor site morbidity, decrease operative time and are readily available. There are numerous materials within this group and, as such, the major subgroups of these materials will be addressed. These include permanent implants, both metallic and nonmetallic, as well as the resorbable materials. Many of these materials are available both in simple sheets or perforated forms.

Silicone: The use of silastic implants and silicone sheets has been extensively documented in the literature (35-42). The positive attributes of this material include low cost, flexibility and ease of handling, while providing adequate support in maintaining orbital contents in large orbital floor fractures (35). There are case series (41) that observed good results without significant complications with silicone use. However, the use of this implant material has been linked with complications. Several case reports $(37-42)$ demonstrated a variety of significant complications. This was further supported by laboratory studies $(36,38-42)$ demonstrating poor incorporation of silicone at the cellular level. A series by Laxenaire et al (38) on 137 patients reported significant complication rates, where $13.8 \%$ of the patients required removal of the implant. Silicone sheets seem to be more prone to the production of a fibrous capsule around the implant, quite similar to that which occurs with breast implants. Due to the orbit's proximity to the mucosa of the maxillary and ethmoid sinuses, the formation of a capsule is a significant risk factor in the development of fistulas, sinus tracts, cysts and infections.

Bioactive glass: Bioactive glass has had numerous studies supporting its potential as an implant $(43,44)$. It has been shown to form a chemical bond with bone tissue and is osteoconductive. Kinnunen et al (43) found that following the repair of 28 orbital floor fractures ( 14 with bioactive glass implants and the other 14 with cartilage), none of the patients in the bioactive glass group developed implant-related complications. Furthermore, they demonstrated better outcomes than the cartilage group, which developed three cases of diplopia, two cases of infraorbital nerve parasthesia and one case of enophthalmos. Aitasalo et al (44), from the same centre, conducted a retrospective review of 36 patients treated from 1995 to 1999 for orbital floor fractures that were repaired with bioactive glass. In this series, there were no implant-associated complications; specifically, no resorption, infection, extrusion or displacement of the implant at the one-year follow-up. As well, computed tomography scan imaging qualitatively demonstrated new bone formation around the implant.

Porous polyethylene: Perforated implant materials facilitate tissue ingrowth and reduce foreign body type reactions, capsule formation and capsule-associated complications. A commonly used perforated material is porous polyethylene sheets or Medpor (Porex, USA) (42,45-48). Dougherty and Wellisz (42) compared silicone with porous polyethylene implants in an animal model for orbital reconstruction. The polyethylene implants exhibited vascular and soft tissue ingrowth through the pores one week following implantation. Mature mucosal growth was also observed. The silicone sheet demonstrated a fibrous tissue reaction at one week and did not fixate to bone or soft tissue. In 1993, Romano et al (46) used porous polyethylene in 140 patients with facial fractures. This material was reported to be easy to work with and the authors observed soft tissue ingrowth with virtually no soft tissue reaction. In their series, there was one case of implant infection requiring removal. Used more specifically for orbital reconstruction, Villarreal et al (47) published their experience with porous polyethylene. In their series of 32 patients, the authors treated four patients with postoperative infections: two of them with cutaneous fistulas and two resolved with systemic antibiotics. One of the four required bone sequestrum resection and one required implant removal. A more general study (36) that examined postoperative infections in craniofacial procedures demonstrated a higher infection rate with the use of porous polyethylene implants, particularly when positioned through the transoral route. This may be of significance because orbital implants are similarly exposed to a mucosal surface, offering an explanation for the higher infection rates in the study from Villarreal et al (47).

Titanium: Titanium is a metallic alloplast that has received much attention in the area of craniofacial reconstruction. It has already proven its worth in dental implants, bone screws and prosthetic implants. A rigid, yet malleable material, the physical properties of titanium make it ideal for the reconstruction of large defects requiring structural rigidity and strength (49-56). Another attractive feature of titanium is its ability to osseointegrate $(54,55)$. A study by Schubert et al (53), using endoscopic visualization and biopsies, examined the incorporation of soft tissue into titanium mesh for orbital and midface reconstruction in eight patients. Soft tissue budding was evident approximately one month postoperatively, with almost complete incorporation of the implant with a mucosal type epithelium before the two-month mark. One patient demonstrated soft tissue coverage at 15 days. Chronic inflammation, however, was noted in these patients during the course of 31 months. A larger study involving 55 patients with 67 orbital fractures, conducted by Gear et al (51), demonstrated that titanium implants maintained adequate reduction for orbital defects larger than $2 \mathrm{~cm}$. This series reported one case of abscess in a patient who received highdose steroids preoperatively. The patient was successfully treated with incision and drainage and concurrent systemic antibiotics. No other implant-related complication was reported after a mean follow-up of 44 months. Sargent and Fulks (52) reconstructed 57 orbits with vitallium mesh (a titanium alloy) with no infection after nine months, even with free 
communication between the implant and paranasal sinuses (52). Mackenzie et al (49) reconstructed 51 orbits with titanium and reported only one case of enophthalmos without any infection after nine months of follow-up. Ellis and Tan (16) compared cross-sectional areas of reconstructed traumatized orbits with the unaffected contralateral orbit. They reported a significantly improved accuracy of reconstruction in orbits reconstructed with titanium than with bone grafts. Long-term follow-up for these cases has yet to be reported.

\section{Resorbable alloplastic materials}

Generally, it can be stated that permanent alloplastic materials are easy to work with and provide good correction of orbital fractures; however, when complications arise, the problems are difficult to overcome and frequently necessitate removal of the implant. Resorbable materials offer the benefits enjoyed by alloplasts, but theoretically eliminate a chronic foreign body reaction and long-term sequelae.

Gelatin film: Gelatin film is manufactured from denatured collagen. In an animal model using cats with surgically created orbital defects, gelatin film was compared with silicone sheets for orbital repair (57). The gelatin film demonstrated decreased implant migration, less inflammatory response and improved healing. A series of 16 patients, presented by Mermer and Orban (58), following the use of gelfilm showed no implantrelated complications and showed what the authors described as acceptable postoperative radiographical results. The defects in their series were small, under $5 \mathrm{~mm}$ in size.

Polyglycolic acid: Biodegradable polyglycolic acid (PGA) is another option as an implant material. PGA loses its structural integrity by two months and is $95 \%$ resorbed by nine months. In 1994, Hatton et al (59) evaluated in vitro growth of bone cells around silicone membranes and PGA. After two weeks in culture, although bone cells were easily dislodged from the silicone membrane, they penetrated the PGA membrane and deposited a calcified collagenous material within the membrane as this membrane underwent resorption. In 2001, Balogh et al (60) presented a series of 18 patients with fractured orbits, with a 24 month follow-up in 10 of these patients. Their series demonstrated no migration of implants, well-corrected orbital volumes and a sole complication of a transient palpebral inflammation that resolved spontaneously. Furthermore, they reported that this material was easy to work with and easily malleable once heated. Five patients with orbital floor defects were repaired via a transantral endoscopic approach using polylactic/polyglycolic acid sheets and demonstrated no graft-related problems (61). Hollier et al (62) used this same material for larger orbital floor defects (over $1 \mathrm{~cm}^{2}$ ). Of 12 patients, nine presented to follow-up after an average of six months. Of these, one patient developed an inflammatory reaction requiring the removal of the implant and two patients developed enophthalmos. Their recommendation was that resorbable implants should not be used for larger defects.

Polydioxanone: Polydioxanone is a synthetic biodegradable polymer. It is currently used as suture material that resorbs approximately six months following implantation. In a study by Piotrowski and Mayer-Zuchi (63), 85 patients with orbital floor defects were corrected using a polydioxanone polymer. They reported adequate reconstruction in $83.5 \%$ of the patients (63). A smaller study by Baumann et al (64) reconstructed 31 orbits using polydioxanone. In their series, one patient required removal of the implant due to hematoma and residual diplopia, and a second patient required partial removal of the implant due to extrusion with subsequent bone grafts to correct an enophthalmos. As well, they reported that seven patients $(22.6 \%)$ developed enophthalmos. The preoperative to postoperative diplopia rate decreased from 25 patients to 10 patients six months postoperatively. Five of the patients who developed enophthalmos had orbital defects larger than $2.5 \mathrm{~cm}$. The authors attributed the enophthalmos to the resultant scar being unable to adequately support the orbital contents. In a series (65) of 16 patients (10 patients with pure blowout fractures and six patients with associated zygomatic fractures), the defects were corrected using polydioxanone. The authors reported an increasing rate of enophthlamos as follow-up increased, reaching $37.5 \%$ of patients by the 36-week mark. Fibrotic sinuses filled with gas and fluid occurred in three cases and one case, respectively. Finally, one patient developed a maxillary sinusitis requiring removal of the remaining implant fragments 16 weeks postoperatively. The authors of this study recommended this material not be used for orbital repair. Recently, a comparative study by Jank et al (66) corrected orbital floors with lyophilized dura $(n=120)$, polydioxanone $(n=81)$ and Ethisorb (Johnson and Johnson, USA) $(n=136)$. The authors reported an enophthalmos rate of $1 \%$ in all three groups, and did not find any statistical difference among the three groups for other parameters, including exophthalmos, reduced bulbous motility and diplopia. There were no reports of any implant-related complications.

\section{CONCLUSIONS}

Most of the materials used in reconstructing the orbit have proven useful and reliable in experienced hands. Unfortunately, the ideal implant material for orbital reconstruction still remains elusive. Autologous implants are associated with potential donor site morbidity, and are in limited supply. Allogenic materials exhibit increased implant resorption and are plagued with the small, but potentially lethal, risk of disease transmission. Permanent implants leave the patient with a foreign body in close proximity to mucosal epithelium. Currently used resorbable materials are unable to provide an adequate skeleton for new bone formation, with the resultant scar too weak to support the overlying orbital contents. In addition, the smooth surface of currently used resorbables has the potential to form a fibrous capsule, possibly resulting in capsulerelated complications.

The ideal material for orbital floor fracture repair is one that is resorbable, osteoconductive, resistant to infection, minimally reactive, does not induce capsule formation, has a halflife which would allow for significant bony ingrowth to occur, and is cheap and readily available. At this time, the authors propose a prospective evaluation of a multilayered collagenbased matrix derived from porcine submucosa as an alternative to current materials for orbital floor reconstruction. Furthermore, a novel technique in fixation of the implant will be examined. Preliminary laboratory data demonstrate this material to be highly osteoconductive on a rat model (unpublished data). Patients with pure orbital floor fractures will be prospectively evaluated clinically and radiologically for aesthetic outcomes, orbital volumes and bony ingrowth at predetermined intervals. 


\section{REFERENCES}

1. Courtney DJ, Thomas S, Whitfield PH. Isolated orbital blowout fractures: Survey and review. Br J Oral Maxillofac Surg 2000;38:496-503.

2. Burnstine MA. Clinical recommendations for the repair of isolated orbital floor fractures: An evidence-based analysis. Ophthalmology 2002;109:1207-13.

3. Bahr W, Bagambisa F, Stom, Schlegel G, Schilli W. Comparison of transcutaneous incisions used for the exposure of the infraorbital rim and orbital floor: A retrospective study. Plast Reconstr Surg 1992;90:585-91.

4. Lee MJ, Kang YS, Yang JY, Lee do Y, Chung YY, Rohrich RJ. Endoscopic transnasal approach for the treatment of medial orbital blow-out fracture: A technique for controlling the fractrured wall with a balloon catheter and Merocel. Plast Reconstr Surg 2002;110:417-28

5. Chowdhury K, Krause GF. Selection of materials for orbital floor reconstruction. Arch Otolaryngol Head Neck Surg 1998;124:1398-401.

6. Young VL, Schuster RH, Harris LW. Intracerebral hematoma complicating split calvarial bone-graft harvesting. Plast Reconstr Surg 1990;86:763-5.

7. Kline RM Jr, Wolfe SA. Complications associated with the harvesting of cranial bone grafts. Plast Reconstr Surg 1995;95:5-20.

8. Iatrou I, Theologie-Lygidakis N, Angelopoulos A. Use of membrane and bone grafts in the reconstruction of orbital fractures. Oral Surg Oral Med Oral Pathol Oral Radiol Endod 2001;91:281-6.

9. Johnson EP, Raftopoulos I. In situ splitting of a rib graft for reconstruction of the orbital floor. Plast Reconstr Surg 1999;103:1709-11.

10. Mintz SM, Ettinger A, Schmakel T, Gleason MJ. Contralateral coronoid process bone grafts for orbital floor reconstruction: An anatomic and clinical study. J Oral Maxillofac Surg 1998;56:1140-5.

11. Kakibuchi M, Fukuda K, Yamada N, et al. A simple method for harvesting a thin iliac bone graft for reconstruction of the orbital wall. Plast Reconstr Surg 2003;111:961-2.

12. Ozaki W, Buchman SR. Volume maintenance of onlay bone grafts in the craniofacial skeleton: Micro-architecture versus embryologic origin. Plast Reconstruc Surg 1998;102:291-9.

13. Glassman RD, Manson PN, Vanderkolk CA, et al. Rigid fixation of internal orbital fractures. Plast Reconstr Surg 1990;86:1103-11.

14. Hwang K, Kita Y. Alloplastic template fixation of blow-out fracture. J Craniofac Surg 2002;13:510-2.

15. Sullivan PK, Rosenstein DA, Holmes RE, Craig D, Manson PN. Bone graft reconstruction of the monkey orbital floor with iliac grafts and titanium mesh plates: A histometric study. Plast Reconstr Surg 1993;91:769-77.

16. Ellis E 3rd, Tan Y. Assessment of internal orbital reconstructions for pure blowout fractures: Cranial bone grafts versus titanium mesh. J Oral Maxillofac Surg 2003;61:442-53.

17. Lin KY, Bartlett SP, Yaremchuk MJ, Fallon M, Grossman RF, Whitaker LA. The effect of rigid fixation on the survival of onlay bone grafts: An experimental study. Plast Reconstr Surg 1990;86:449-56.

18. Philips JH, Rahn BA. Fixation effects on membranous and endochondral onlay bone graft revascularization and bone deposition. Plast Reconstr Surg 1990;85:891-7.

19. Zins JE, Whitaker LA. Membranous versus endochondral bone: Implications for craniofacial reconstruction. Plast Reconstr Surg 1983;72:778-85.

20. Kraus M, Gatot A, Fliss D. Repair of traumatic inferior orbital wall defects with nasoseptal cartilage. J Oral Maxillofac Surg 2001;59:1397-401.

21. Constantian MB. Use of auricular cartilage in orbital floor reconstruction. Plast Reconstr Surg 1982;69:951-5.

22. Dost P. [Orbital floor reconstruction with autologous periosteum transplant]. Laryngorhinootologie 1996;75:57-8.

23. Celikoz B, Duman H, Selmanpakoglu N. Reconstruction of the orbital floor with lyophilized tensor fascia lata. J Oral Maxillofac Surg 1997;55:240-4.

24. Neigel JM, Ruzicka PO. Use of demineralised bone implants in orbital and craniofacial reconstruction and a review of the literature. Ophthal Plast Reconstr Surg 1996;12:108-20.

25. Waite PD, Clanton JT. Orbital floor reconstruction with lyophilized dura. J Oral Maxillofac Surg 1988;46:727-30.
26. Guerra MF, Perez JS, Rodriguez-Campo JF, Gias LN. Reconstruction of orbital fractures with dehydrated human dura matter. I Oral Maxillofac Surg 2000;58:1361-6.

27. Bevivino JR, Nguyen PN, Yen LJ. Reconstruction of traumatic orbital floor defects using irradiated cartilage homografts. Ann Plast Surg 1994;33:32-7.

28. Chen JM, Zingg M, Laedrach K, Raveh J. Early surgical intervention for orbital floor fractures: A clinical evaluation of lyophilized dura and cartilage reconstruction. J Oral Maxillofac Surg 1992;50:935-41.

29. Morax S, Hurbli T, Smida R. [Bovine heterologous bone graft in orbital surgery]. Ann Chir Plast Esthet 1993;38:445-50.

30. Campbell DG, Li P. Sterilization of HIV with irradiation: Relevance to infected bone allografts. Aust N Z J Surg 1999;69:517-21.

31. Aho AJ, Hirn M, Aro HT, Heikkila JT, Meurman O. Bone bank service in Finland. Experience of bacteriologic, serologic and clinical results of the Turku Bone Bank 1972-1995. Acta Orthop Scand 1998;69:559-65

32. Nakumura Y, Aso E, Yanagawa H. Relative risk of CreutzfeldtJakob disease with cadaveric dura transplantation in Japan. Neurology 1999;53:218-20.

33. Munoz Guerra MF. Human dura matter and Creutzfeldt-Jakob Disease. J Oral Maxillofac Surg 2001;59:595.

34. Taguchi F, Tamai Y, Uchida K, et al. Proposal for a procedure for complete inactivation of the Creutzfeldt-Jakob disease agent. Arch Virol 1991;119:297-301. (Erratum in: 1992;122:411)

35. Huag RH, Nuveen E, Bredbenner T. An evaluation of the support provided by common internal orbital reconstruction materials. J Oral Maxillofac Surg 1999;57:564-70.

36. Fialkov JA, Holy C, Forrest CR, Philips JH, Antonyshyn OM. Postoperative infections in craniofacial reconstructive procedures. J Craniofacial Surg 2001;12:362-8.

37. Schmidt BL, Lee C, Young DM, O’Brien J. Infraorbital squamous epthilial cyst: An unusual complication of Silastic implantation. J Craniofac Surg 1998;9:452-5.

38. Laxenaire A, Levy J, Blanchard P, Lerondeau JC, Tesnier F, Scheffer P. [Complications of silastic implants used in orbital repair]. Rev Stomatol Chir Maxillofac 1997;98(Suppl 1):96-9.

39. Klisovic DD, Katz SE, Lubow M. The wayward implant: Orbital silicone plate extrusion associated with squamous epithelial downgrowth and infection. Orbit 2002;21:149-54.

40. Liu D, Al-Sadhan Y. Orbital floor implant migration across the ethmoidal sinuses and nasal septum. Am J Ophthalmol 1999;128:122-3.

41. Mwanza JC, Ngoy DK, Kayembe DL. Reconstruction of orbital floor blow-out fractures with silicone implant. Bull Soc Belge Ophtalmol 2001;280:57-61.

42. Dougherty WR, Wellisz T. The natural history of alloplastic implants in orbital floor reconstruction: An animal model. J Craniofac Surg 1994;5:26-33.

43. Kinnunen I, Aitasalo K, Pollonen M, Varpula M. Reconstruction of orbital floor fractures using bioactive glass. J Craniomaxillofac Surg 2000;28:229-34.

44. Aitasalo K, Kinnunen I, Palmgren J, Varpula M. Repair of orbital floor fractures with bioactive glass implants. J Oral Maxillofac Surg 2001;59:1390-6.

45. Yaremchuk MJ. Facial reconstruction using porous polyethylene implants. Plast Reconstr Surg 2003;111:1818-27.

46. Romano JJ, Iliff NT, Manson PN. Use of Medpor porous polyethylene implants in 140 patients with facial fractures. J Craniofac Surg 1993;4:142-7.

47. Villarreal PM, Monje F, Morillo AJ, Junquera LM, Gonzalez C, Barbon JJ. Porous polyethylene implants in orbital floor reconstruction. Plast Reconstr Surg 2002;109:877-87.

48. Gosain AK, Persing JA. Biomaterials in the face: Benefits and risks. J Craniofac Surg 1999;10:404-14.

49. Mackenzie DJ, Arora B, Hansen J. Orbital floor repair with titanium mesh screen. J Carniomaxillofac Trauma 1999;5:9-18.

50. Park HS, Kim YK, Yoon CH. Various applications of titanium mesh screen implant to orbital wall fractures. J Craniofac Surg 2001;12:555-60.

51. Gear AJ, Lokeh A, Aldridge JH, Migliori MR, Benjamin CI, Schubert W. Safety of titanium mesh for orbital reconstruction. Ann Plast Surg 2002;48:1-9. 
52. Sargent LA, Fulks KD. Reconstruction of internal orbit fractures with Vitallium mesh. Plast Reconstr Surg 1991;88:31-8.

53. Schubert W, Gear AJ, Lee C, et al. Incorporation of titanium mesh in orbital and midface reconstruction. Plast Reconstr Surg 2002;110:1022-32.

54. Mofid MM, Thompson RC, Pardo CA, Manson PN, Vander Kolk CA. Biocompatibility of fixation materials in the brain. Plast Reconstr Surg 1997;100:14-22.

55. Ungersbock A, Pohler O, Perren SM. Evaluation of soft tissue interface at titanium implants with different surface treatments: Experimental study on rabbits. Biomed Mater Eng 1994;4:317-25.

56. Hughes CW, Page K, Bibb R, Taylor J, Revington P. The custommade titanium orbital floor prosthesis in reconstruction for orbital floor fractures. Br J Oral Maxillofac Surg 2003;41:50-3. (Erratum in: 2003;41:209)

57. Parkin JL, Stevens MH, Stringham JC. Absorbable gelatin film verses silicone rubber sheeting in orbital fracture treatment. Laryngoscope 1987;97:1-3.

58. Mermer RW, Orban RE Jr. Repair of orbital floor fractures with absorbable gelatin film. J Craniomaxillofac Trauma 1995;1:30-4.

59. Hatton PV, Walsh J, Brook IM. The response of cultured bone cells to resorbable polyglycolic acid and silicone membranes for use in orbital floor fracture repair. Clin Mater 1994;17:71-80.
60. Balogh C, Lucas R, Kraft T, Breton P, Freidel M. [Lactic acid polymer implants in the repair of traumatic defects of the orbital floor]. Rev Stomatol Chir Maxillofac 2001;102:109-14.

61. Persons BL, Wong GB. Transantral endoscopic orbital floor repair using resorbable plate. J Craniofac Surg 2002;13:483-8.

62. Hollier LH, Rogers N, Berzin E, Stal S. Resorbable mesh in the treatment of orbital floor fractures. J Craniofac Surg 2001; 12:242-6.

63. Piotrowski WP, Mayer-Zuchi U. The use of polyglactin 910-polydioxanon in the treatment of defects of the orbital roof. J Oral Maxillofac Surg 1999;57:1301-6.

64. Baumann A, Burggasser G, Gauss N, Ewers R. Orbital floor reconstruction with an alloplastic resorbable polydiaxanone sheet. Int J Oral Maxillofac Surg 2002;31:367-73.

65. Kontio R, Suuronen R, Salonen O, Paukku P, Konttinen T, Lindqvist C. Effectiveness of operative treatment of internal orbital wall fracture with polydiaxanone implant. Int J Oral Maxillofac Surg 2001;30:278-85

66. Jank S, Emshoff R, Schuchter B, Strobl H, Brandlmaier I, Norer B. Orbital floor recontruction with flexible Ethisorb patches: A retrospective long-term follow-up study. Oral Surg Oral Med Oral Pathol Oral Radiol Endod 2003;95:16-22. 